\title{
Chronic Immune Thrombocytopenic Purpura in a Young Female with Rheumatoid Arthritis (Unusual Course)
}

\author{
Sara Elhadari ${ }^{*}$, Asif Hashmi ${ }^{1}$, Hani Hussein ${ }^{2}$ \\ ${ }^{1}$ Department of Medicine, Armed Forces Hospital, Jubail, Saudi Arabia \\ ${ }^{2}$ Department of Family Medicine, Armed Forces Hospital, Jubail, Saudi Arabia \\ Email: *sara_elhadari@yahoo.com, babahashmi@hotmail.com, hanihussain@hotmail.com
}

How to cite this paper: Elhadari, S., Hashmi, A. and Hussein, H. (2018) Chronic Immune Thrombocytopenic Purpura in a Young Female with Rheumatoid Arthritis (Unusual Course). Case Reports in Clinical Medicine, 7, 557-566.

https://doi.org/10.4236/crcm.2018.711050

Received: October 11, 2018

Accepted: November 12, 2018

Published: November 15, 2018

Copyright $\odot 2018$ by authors and Scientific Research Publishing Inc. This work is licensed under the Creative Commons Attribution International License (CC BY 4.0).

http://creativecommons.org/licenses/by/4.0/

\begin{abstract}
We present a case of a 29-year-old female from Sudan, who was diagnosed with rheumatoid arthritis (RA) in 2005 and with immune thrombocytopenic purpura (ITP) in 2009. The ITP immediately followed using, for four weeks, a combination of medications that included rifampicin. The platelets count continued to be low thereafter. During the year following her diagnosis with ITP, she reported gradual improvement in her joints symptoms, which continued during her pregnancy in 2011. Following puerperium, her chronic ITP resolved completely; however, her joint disease flared up few months later. To our knowledge, there are no reported cases of chronic ITP, which were drug induced at first in a patient of RA except with gold therapy. Similarly, there are no reports on cases that recovered from chronic ITP after delivery. Finally, this case highlights the impact different coexisting autoimmune diseases may have on each other regarding course and prognosis.
\end{abstract}

\section{Keywords}

ITP, Immune Thrombocytopenic Purpura, Drug-Induced

Thrombocytopenia, DITP, Pregnancy, Rheumatoid Arthritis

\section{Introduction}

The occurrence of chronic Immune Thrombocytopenic Purpura (ITP) in association with Rheumatoid Arthritis (RA) is a rare entity, but has been reported in literature [1]-[9]. Similarly, drug induced thrombocytopenia in patients with RA has also been reported with various medications including disease modifying antirheumatic drugs (DMARDs) and Biologics [10]-[23]. The significance of re- 
porting this case is to cast light over an unusual persistence of thrombocytopenia in a patient with RA, which appears most likely drug induced. It also raises an intriguing question about the prognosis of autoimmune diseases in general: the appearance and disappearance of ITP was preceded by using a regimen that included rifampicin and childbirth respectively, which may suggest causation. Furthermore, this case illustrates an unusual impact of a secondary autoimmune condition (ITP) on a pre-existing primary autoimmune condition (RA) with regards to the severity and activity of the latter. The mechanisms that may have underpinned this is unclear; however, it is possible that it involved complex immunological mechanisms.

\section{Case Presentation}

In March 2005, a young female doctor was diagnosed with RA at the age of 23 ,based on having more than two months history of multiple joints pain, swelling, and morning stiffness lasting more than an hour. The symptoms mainly involved the small joints of both hands and wrists. Other features were strongly positive rheumatoid factor, high antinuclear antibody titre at 1/160 and family history of autoimmune diseases. Anti cardiolipin and lupus anticoagulant were negative, other serology were not available. Routine blood tests and hands $\mathrm{x}$ ray were normal. In subsequent visits, she was prescribed sulfasalazine $500 \mathrm{mg}$ once daily for a week then increased gradually to 1 gram twice daily over a month. At some point, she was prescribed methotrexate, but she deferred using it.

In 2009, she self-prescribed a regimen in an attempt to treat her arthritis. This treatment was based on a theory originally conceived and presented by Dr Roger Wyburn-Mason who suggested that all rheumatic diseases are caused by amoeba and thus can be neutralized by using antibiotics. The regimen used by the patient included rifampicin $600 \mathrm{mg}$ once a day for a month, metronidazole $2 \mathrm{~g}$ for two days in a week for a month and allopurinol $300 \mathrm{mg}$ daily for a week. Two weeks after the regimen had ended; she started experiencing easy bruising and petechial rashes appearing on both thighs and arms with minor trauma. These got worse during the next two weeks; they occurred spontaneously and became much larger and associated with gum bleeding without provocation and menorrhagia. She was off medication during that period except for paracetamol, when needed. A complete blood count turned out to be normal apart from a very low platelets count of $4 \times 10^{3} / \mu \mathrm{L}$. She was transfused two pints of platelets at a local hospital in Sudan, as intravenous immunoglobulin (IVIG) was very expensive and difficult to obtain. A bone marrow examination was suggested after repeating her labs (Table 1), however, the patient refused and opted to start corticosteroids at her own. Her platelet count increased gradually with prednisolone $40 \mathrm{mg}$ once daily, and after two weeks, it reached $63 \times 10^{3} / \mu \mathrm{L}$, only to drop to below $20 \times 10^{3} / \mu \mathrm{L}$ after tapering the steroids.

During the year 2010, she was constantly anaemic (haemoglobin levels between 8.5 to $9.8 \mathrm{~g} / \mathrm{dl}$ ) due to menorrhagia and occasional mild nose and gum 
Table 1. Laboratory values at diagnosis of ITP.

\begin{tabular}{|c|c|c|}
\hline Laboratory test & Value & Reference Range \\
\hline \multicolumn{3}{|c|}{ Haematology } \\
\hline Haemoglobin (g/dl) & 12.6 & $11.0-16.0$ \\
\hline Haematocrit (\%) & 40.8 & $35.0-48.0$ \\
\hline RBC (Million/ $\mu \mathrm{L})$ & 4.49 & $4.5-5.5$ \\
\hline $\operatorname{MCV}(\mathrm{fl})$ & 90.9 & $80.0-92.0$ \\
\hline $\mathrm{MCH}(\mathrm{pg})$ & 28.1 & $27.0-31.0$ \\
\hline $\mathrm{MCHC}(\mathrm{g} / \mathrm{dl})$ & 30.9 & $31.0-33.0$ \\
\hline Reticulocytes Count (\%) & 3 & $0.5-2.5$ \\
\hline Platelets $\left(\times 10^{3} / \mu \mathrm{L}\right)$ & 9 & $150-450$ \\
\hline Comment & Thrombocytopenia with no aggregation & \\
\hline $\mathrm{WBC}\left(\times 10^{3} / \mu \mathrm{L}\right)$ & 3.6 & $4.00-11.00$ \\
\hline \multicolumn{3}{|l|}{ Differential: } \\
\hline Neutrophils $\left(\times 10^{3} / \mu \mathrm{L}\right)$ & 1.9 & $1.80-6.80$ \\
\hline Lymphocytes $\left(\times 10^{3} / \mu \mathrm{L}\right)$ & 1.5 & $1.20-4.90$ \\
\hline Monocytes $\left(\times 10^{3} / \mu \mathrm{L}\right)$ & 0.1 & $0.10-0.80$ \\
\hline Eosinophils $\left(\times 10^{3} / \mu \mathrm{L}\right)$ & 0.1 & $0.10-0.40$ \\
\hline \multicolumn{3}{|l|}{ APTT } \\
\hline APTT (Sec) & 30 & $30-36$ \\
\hline Control (Sec) & 31 & $30-36$ \\
\hline \multicolumn{3}{|c|}{ Chemistry } \\
\hline Serum Creatinine $(\mathrm{mg} / \mathrm{dl})$ & 0.6 & $0.5-0.9$ \\
\hline Blood Urea (mg/dl) & 31.9 & \\
\hline \multicolumn{3}{|c|}{ Immunology } \\
\hline Direct Coombs Test & Negative & \\
\hline \multicolumn{3}{|c|}{ Urine Analysis } \\
\hline \multicolumn{3}{|l|}{ Chemical-Macroscopic Exam } \\
\hline Colour & Yellow & \\
\hline Reaction & Alkaline & \\
\hline Inspection & Clear & \\
\hline Sugar & Negative & \\
\hline Acetone & Negative & \\
\hline Protein & Negative & \\
\hline Bilirubin & Negative & \\
\hline Urobilinogen & Normal & \\
\hline Nitrate & Negative & \\
\hline \multicolumn{3}{|l|}{ Microscopic Exam } \\
\hline Pus cells & $0-1$ & \\
\hline $\mathrm{RBC}$ & $1-2$ & \\
\hline Epithelial Cells & {$[$ few $]$} & \\
\hline
\end{tabular}


Continued

\begin{tabular}{cc}
\hline Crystal & Absent \\
Cast & Absent \\
Yeast cells & Absent \\
Mucous thread & Absent \\
Others & No others \\
\hline
\end{tabular}

BC: Red Blood Cells, MCV: Mean Corpuscular Volume, MCH: Mean Corpuscular Haemoglobin, MCHC: Mean Cell Haemoglobin Concentration, WBC: White blood cells, APTT: Activated Partial Thromboplastin Time.

bleeds. Her platelet count was fluctuating between $20 \times 10^{3} / \mu \mathrm{L}$ and $30 \times 10^{3} / \mu \mathrm{L}$ without the use of steroids. Surprisingly, her joint pains were getting better slowly and gradually.

In 2011, she got pregnant while she was on high dose prednisolone for one month, which she took to minimize expected bleeding from a surgical tooth extraction. During her pregnancy, her platelets count continued to be less than 30 $\times 10^{3} / \mu \mathrm{L}$ until the last trimester when it dropped to less than $20 \times 10^{3} / \mu \mathrm{L}$ (Table 2). All other ante-natal tests including trans-cranial fetal ultrasound were normal.

Six weeks before her expected date of delivery, she was started on $60 \mathrm{mg}$ prednisolone daily in anticipation of labour bleeds, which rose platelets count to 260 $\times 10^{3} / \mu \mathrm{L}$. She gave birth to a healthy baby boy weighing $3.2 \mathrm{~kg}$ by normal vaginal delivery. His platelet count at delivery was normal and remained so when tested after one month. The patient continued prednisolone for another six weeks after delivery to prevent expected heavy puerperal bleeding. Surprisingly, after tapering and discontinuing the prednisolone, her platelet counts remained normal without any treatment after puerperium. It continued to be so ever since (Table 3). Conversely, as her chronic ITP ceased to be, overtime her joint pains started to reappear with a full-blown picture of RA six months after delivery.

\section{Discussion}

Thrombocytopenia in patients with RA has several differential diagnoses, including chronic ITP, Felty syndrome, systemic lupus erythematosus (SLE), antiphospholipid syndrome (APLS), drug-induced thrombocytopenia (DITP), and infections. Physicians are generally able to reach the diagnosis of chronic ITP after excluding other causes of low platelets and performing sets of investigations including a bone marrow examination. Antiplatelet antibodies testing is not widely available, therefore, it is not essential for making the diagnosis. Patients with chronic ITP generally respond well to steroids and the condition is termed chronic if it continues for more than twelve months.

Certain medications are known to cause low platelets; however, the count is expected to rise shortly after discontinuing the offending drug. Although, occasionally this might not be the case and platelet count might continue to be low after drug cessation for weeks or even months. The longest period reported in 
Table 2. Complete blood count at 36 weeks gestation.

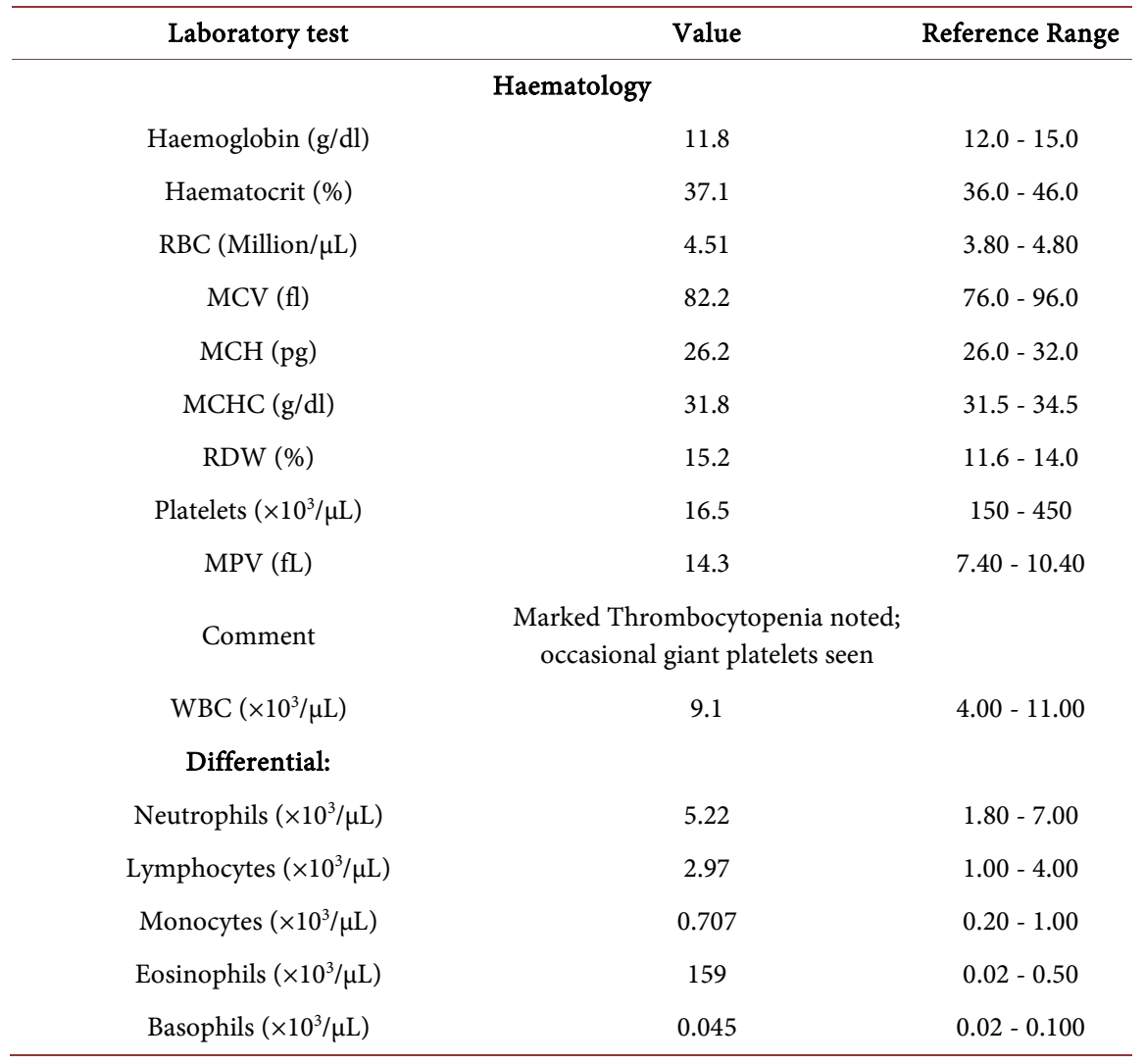

RBC: Red Blood Cells, MCV: Mean Corpuscular Volume, MCH: Mean Corpuscular Haemoglobin, MCHC: Mean Cell Haemoglobin Concentration, RDW: Red Cell Distribution Width, MPV: Mean Platelet Volume, WBC: White blood cells.

Table 3. Complete blood count at eight weeks after delivery.

\begin{tabular}{|c|c|c|}
\hline Laboratory test & Value & Reference Range \\
\hline \multicolumn{3}{|c|}{ Haematology } \\
\hline Haemoglobin (g/dl) & 13.8 & $12.0-15.0$ \\
\hline Haematocrit (\%) & 38.7 & $36.0-46.0$ \\
\hline RBC (Million/ $\mu \mathrm{L})$ & 4.75 & $3.80-4.80$ \\
\hline $\operatorname{MCV}(\mathrm{fl})$ & 81.5 & $76.0-96.0$ \\
\hline $\mathrm{MCH}(\mathrm{pg})$ & 29 & $26.0-32.0$ \\
\hline $\mathrm{MCHC}(\mathrm{g} / \mathrm{dl})$ & 35.6 & $31.5-34.5$ \\
\hline RDW (\%) & 12.1 & $11.6-14.0$ \\
\hline Platelets $\left(\times 10^{3} / \mu \mathrm{L}\right)$ & 317 & $150-450$ \\
\hline MPV (fl) & 8.12 & $7.40-10.40$ \\
\hline $\mathrm{WBC}\left(\times 10^{3} / \mu \mathrm{L}\right)$ & 9.53 & $4.00-11.00$ \\
\hline \multicolumn{3}{|c|}{ Differential } \\
\hline Neutrophils $\left(\times 10^{3} / \mu \mathrm{L}\right)$ & 5.47 & $1.80-7.00$ \\
\hline Lymphocytes $\left(\times 10^{3} / \mu \mathrm{L}\right)$ & 3.39 & $1.00-4.00$ \\
\hline
\end{tabular}




$\begin{array}{lll}\text { Monocytes }\left(\times 10^{3} / \mu \mathrm{L}\right) & 0.436 & 0.20-1.00 \\ \text { Eosinophils }\left(\times 10^{3} / \mu \mathrm{L}\right) & 0.167 & 0.02-0.50 \\ \text { Basophils }\left(\times 10^{3} / \mu \mathrm{L}\right) & 0.063 & 0.02-0.10\end{array}$

RBC: Red Blood Cells, MCV: Mean Corpuscular Volume, MCH: Mean Corpuscular Haemoglobin, MCHC Mean Cell Haemoglobin Concentration, RDW: Red Cell Distribution Width, MPV: Mean Platelet Volume, WBC: White blood cells.

literature of this, to the best of our knowledge, was of a patient who continued to have low platelets for two years after sulfamethoxazole was stopped [24]. Another report demonstrated chronic thrombocytopenia lasting for 18 years after gold injection therapy in a patient with RA. However, it is worth noting that gold is known to persist in body tissues for years after injections indicating the persistence of antigens triggering thrombocytopenia [25]. There are a number of reports on rifampicin induced thrombocytopenia in patients with tuberculosis [26] [27] [28] [29], however, to our knowledge, there are no similar reports related to metronidazole. Few cases were associated with allopurinol, but these were rarely isolated thrombocytopenia [30] [31].

Well-established chronic ITP with pregnancy has been reported frequently; however, most studies focused on maternal complications, fetal outcome, and management during pregnancy and labour. To our knowledge, there are no reported cases of spontaneous improvement in platelets count after labour in patients with confirmed chronic ITP diagnosed before pregnancy, not to be mistaken with gestational or incidental thrombocytopenia, which is the commonest type of thrombocytopenia during pregnancy and could be considered as transitory physiological phenomenon during the second and third trimester [32] [33] [34].

Another key feature of this case is the gradual remission of RA symptoms after the onset of thrombocytopenia, and then the re-emergence of these symptoms few months after labour concomitantly with the return of normal platelet count. Although there was no formal assessment from a rheumatologist to confirm the alleged improvement in joint disease, the patient account confirms not having any joints pain, swelling or stiffness after a period of initial gradual improvement when she had thrombocytopenia. Reviewing the data, there are no reports of similar occurrences in patients with multiple autoimmune diseases or overlap syndromes highlighting any sort of improvement or worsening of a primary autoimmune disease after diagnosing a secondary one during its course. Nonetheless, it is well established that RA symptoms can improve during pregnancy and flare up after delivery [35] [36] [37].

\section{Case Analysis}

This case outlines a number of learning points: Firstly, it appears that in a setting of dysfunctional immunological responses and autoreactive susceptibility, drug induced thrombocytopenia may persist for more than 12 months contrary to 
Table 4. Complete blood count before the regimen.

\begin{tabular}{|c|c|c|}
\hline Laboratory test & Value & Reference Range \\
\hline \multicolumn{3}{|c|}{ Haematology } \\
\hline Haemoglobin (g/dl) & 14.5 & $11.5-15.5$ \\
\hline Haematocrit (\%) & 43 & $33.0-45.0$ \\
\hline RBC(Million/ $\mu \mathrm{l})$ & 5.06 & $3.6-5.01$ \\
\hline $\operatorname{MCV}(\mathrm{fl})$ & 85 & $80-99$ \\
\hline $\mathrm{MCH}(\mathrm{pg})$ & 29 & $27-32$ \\
\hline $\operatorname{MCHC}(\mathrm{g} / \mathrm{dl})$ & 33.7 & $32.0-36.0$ \\
\hline RDW (\%) & 14.6 & $11.5-15.5$ \\
\hline Platelets $\left(\times 10^{3} / \mu \mathrm{L}\right)$ & 298 & $145-400$ \\
\hline MPV (fl) & 9.8 & $7.40-11.30$ \\
\hline $\mathrm{WBC}\left(\times 10^{3} / \mu \mathrm{L}\right)$ & 3.5 & $4.00-11.00$ \\
\hline \multicolumn{3}{|c|}{ Differential } \\
\hline Neurophils $\left(\times 10^{3} / \mu \mathrm{L}\right)$ & 1.47 & $1.80-7.00$ \\
\hline Lymphocytes $\left(\times 10^{3} / \mu \mathrm{L}\right)$ & 1.82 & $1.00-3.20$ \\
\hline Monocytes $\left(\times 10^{3} / \mu \mathrm{L}\right)$ & 0.07 & $0.00-0.80$ \\
\hline Eosinophils $\left(\times 10^{3} / \mu \mathrm{L}\right)$ & 0.14 & $0.00-0.40$ \\
\hline Basophils $\left(\times 10^{3} / \mu \mathrm{L}\right)$ & 0.00 & $0.00-0.20$ \\
\hline
\end{tabular}

C: Red Blood Cells, MCV: Mean Corpuscular Volume, MCH: Mean Corpuscular Haemoglobin, MCHC: Mean Cell Haemoglobin Concentration, RDW: Red Cell Distribution Width, MPV: Mean Platelet Volume, WBC: White blood cells.

current commonly accepted views. Despite the fact that the thrombocytopenia in our case was not confirmed to be drug induced by laboratory methods, we believe there was a strong correlation in the history between the drug administration and the fall in platelet count though symptoms were delayed for two weeks after discontinuing the regimen. In addition to the correlation, the patient provided a complete blood count result, done two weeks prior to the initiation of the offending medications, showing a normal platelet count (Table 4). One may question the possibility of overlap syndrome in this particular case, however, the administration of rifampicin just few weeks before thrombocytopenia favours DITP, which triggered chronic ITP. Secondly, the emergence of a new autoimmune condition in a patient with pre-existing one could have an impact on the former condition, which can be remission such as in this case. Thirdly, the case challenges currently held views on the prognosis of chronic ITP; which, once underlying mechanisms are established if further probed and sought, may change the management and psychological impact of the disease on those affected. The impact of pregnancy and labour on different autoimmune diseases, although poorly understood, can provide an understanding of immunological mechanisms that may underpin autoimmunity. 


\section{Acknowledgements}

We appreciate the help of software developer, Mrs Hagir Elhadari, in preparing tables for the case report.

\section{Ethical Consideration}

Informed consent was obtained from the patient to report the case.

\section{Conflicts of Interest}

The authors declare no conflicts of interest regarding the publication of this paper.

\section{References}

[1] Komoğlu, S., Silte, D., Sertbaş, M., Sertbaş, Y. and Özdemir, A. (2015) Methorexate Therapy in a Patient with Rheumatoid Arthritis Complicated by Idiopathic Thrombocytopenic Purpura. European Journal of Rheumatology, 2, 39.

https://doi.org/10.5152/eurjrheumatol.2014.14065

[2] Horino, T., Sasaoka, A., Takao, T., Taguchi, T., Maruyama, H., et al. (2005) Immune Thrombocytopenic Purpura Associated with Rheumatoid Arthritis: Case Report. Clinical Rheumatology, 24, 641-644. https://doi.org/10.5152/eurjrheumatol.2014.14065

[3] Ustun, C., Kallab, A., Loebl, D., Jillela, A., Majewski, B., et al. (2002) Rheumatoid Arthritis and Immune Thrombocytopenia: A Report of Two Cases. Clinical Rheumatology, 21, 543-544. https://doi.org/10.1007/s100670200136

[4] Ichikawa, N., Harigai, M., Nakajima, A., Hara, M. and Kamatani, N. (2001) Immune Thrombocytopenic Purpura Associated with Rheumatoid Arthritis-A Report of Five Cases and Review of The Literature. Modern Rheumatology, 11, 246-250. https://doi.org/10.3109/s101650170013

[5] Yamada, Y. and Kuroe, K. (1991) A Case of Rheumatoid Arthritis Complicated with Idiopathic Thrombocytopenic Purpura and Hashimoto's Disease. Ryumachi [Rheumatism], 31, 413-419.

[6] Dasgupta, B. and Grahame, R. (1989) Treatment with Danazol for Refractory Thrombocytopenia in Rheumatoid Arthritis. Rheumatology, 28, 550-552. https://doi.org/10.1093/rheumatology/28.6.550

[7] Kazama, Y.I., Iwamoto, M., Saito, T., Haraguchi, K. and Onaya, T. (1988) Rheumatoid Arthritis Associated with Severe Thrombocytopenia. Japanese Journal of Clinical Immunology, 11, 309-314. https://doi.org/10.2177/jsci.11.309

[8] Sugimoto, M., Horie, S., Abe, S., Ishiyama, T., Miyayama, T., et al. (1988) A Case of Rheumatoid Arthritis Complicated with Idiopathic Thrombocytopenic Purpura. [Rinsho Ketsueki]. The Japanese Journal of Clinical Hematology, 29, 359.

[9] Misumi, K. (1988) A Case of Idiopathic Thrombocytopenic Purpura with Rheumatoid Arthritis. Naika, 61, 789-792.

[10] Narayan, N., Rigby, S. and Carlucci, F. (2017) Sulfasalazine Induced Immune Thrombocytopenia in a Patient with Rheumatoid Arthritis. Clinical Rheumatology, 36, 477-479. https://doi.org/10.1007/s10067-016-3420-9

[11] Nagai, Y., Yokogawa, N., Shimada, K. and Sugii, S. (2016) Severe Thrombocytopenia Induced by First Infliximab Administration for Rheumatoid Arthritis. American 
Journal of Therapeutics, 23, e1933-e1937. https://doi.org/10.1097/MJT.0000000000000422

[12] Navarro-Millán, I., Singh, J.A. and Curtis, J.R. (2012) Systematic Review of Tocilizumab for Rheumatoid Arthritis: A New Biologic Agent Targeting the Interleukin-6 Receptor. Clinical Therapeutics, 34, 788-802.

https://doi.org/10.1016/j.clinthera.2012.02.014

[13] Kremer, J.M., Bloom, B.J., Breedveld, F.C., Coombs, J.H., Fletcher, M.P., et al. (2009) The Safety and Efficacy of a JAK Inhibitor in Patients with Active Rheumatoid Arthritis: Results of a Double-Blind, Placebo-Controlled Phase IIa Trial of Three Dosage Levels of CP-690,550 versus Placebo. Arthritis \& Rheumatism: Official Journal of the American College of Rheumatology, 60, 1895-1905. https://doi.org/10.1002/art.24567

[14] Pathare, S.K., Heycock, C. and Hamilton, J. (2006) TNF $\alpha$ Blocker-Induced Thrombocytopenia. Rheumatology, 45, 1313-1314.

https://doi.org/10.1093/rheumatology/kel204

[15] Kinder, A.J., Hassell, A.B., Brand, J., Brownfield, A., Grove, M. and Shadforth, M.F. (2005) The Treatment of Inflammatory Arthritis with Methotrexate in Clinical Practice: Treatment Duration and Incidence of Adverse Drug Reactions. Rheumatology, 44, 61-66. https://doi.org/10.1093/rheumatology/keh512

[16] Jih, D.M. and Werth, V.P. (1998) Thrombocytopenia after a Single Test Dose of Methotrexate. Journal of the American Academy of Dermatology, 39, 349-351. https://doi.org/10.1016/S0190-9622(98)70387-1

[17] Franck, H., Rau, R. and Herborn, G. (1996) Thrombocytopenia in Patients with Rheumatoid Arthritis on Long-Term Treatment with Low Dose Methotrexate. Clinical Rheumatology, 15, 163-167. https://doi.org/10.1007/BF02230334

[18] Adachi, J.D., Bensen, W.G., Kassam, Y., Powers, P.J., Bianchi, F.A., et al. (1987) Gold Induced Thrombocytopenia: 12 Cases and a Review of the Literature. Seminars in Arthritis and Rheumatism, 16, 287-293.

[19] Von Dem Borne, A.E., Pegels, J.G., Van Der Stadt, R.J., Van Der Plas-Van Dalen, C.M. and Helmerhorst, F.M. (1986) Thrombocytopenia Associated with Gold Therapy: A Drug-Induced Autoimmune Disease? British Journal of Haematology, 63, 509-516. https://doi.org/10.1111/j.1365-2141.1986.tb07528.x

[20] Thomas, D., Gallus, A.S., Brooks, P.M., Tampi, R., Geddes, R. and Hill, W. (1984) Thrombokinetics in Patients with Rheumatoid Arthritis Treated with D-Penicillamine. Annals of the Rheumatic Diseases, 43, 402. https://doi.org/10.1136/ard.43.3.402

[21] Coblyn, J.S., Weinblatt, M., Holdsworth, D. and Glass, D. (1981) Gold-Induced Thrombocytopenia: A Clinical and Lmmunogenetic Study of Twenty-Three Patients. Annals of Internal Medicine, 95, 178-181. https://doi.org/10.7326/0003-4819-95-2-178

[22] Stafford, B.T. and Crosby, W.H. (1978) Late Onset of Gold-Induced Thrombocytopenia: With a Practical Note on the Injections of Dimercaprol. JAMA, 239, 50-51. https://doi.org/10.1001/jama.1978.03280280050029

[23] Deren, B., Masi, R., Weksler, M. and Nachman, R.L. (1974) Gold-Associated Thrombocytopenia: Report of Six Cases. Archives of Internal Medicine, 134, 1012 1015. https://doi.org/10.1001/archinte.1974.00320240046004

[24] Aster, R.H. (2000) Can Drugs Cause Autoimmune Thrombocytopenic Purpura? Seminars in Hematology, 37, 229-238.

https://doi.org/10.1016/S0037-1963(00)90101-X 
[25] Gottlieb, N. (1975) Letter: Chronic Thrombocytopenia Following Gold Therapy. Archives of Internal Medicine, 135, 1622a-1623a. https://doi.org/10.1001/archinte.135.12.1622a

[26] Neino, M.M., Tummino, C., Gouitaa, M. and Chanez, P. (2013) Thrombocytopenia Induced by Rifampicin Not Previously Sensitized: A Case Presentation. Revue des Maladies Respiratoires, 30, 785-788.

[27] Bansal, R., Sharma, P.K. and Sharma, A. (2013) A Case of Thrombocytopenia Caused by Rifampicin and Pyrazinamide. Indian Journal of Pharmacology, 45, 405. https://doi.org/10.4103/0253-7613.114998

[28] Agrawal, A., Gutch, M., Jain, N. and Singh, A. (2012) Do Not Miss Rifampicin-Induced Thrombocytopenic Purpura. BMJ Case Reports, 2012, bcr1220115282. https://doi.org/10.1136/bcr.12.2011.5282

[29] Mori, M., Fujikawa, T., Uenami, T., Sugano, T., Kagami, S.I., et al. (2011) A Case of Acute and Severe Thrombocytopenia Due to Readministration of Rifampicin. Journal of Infection and Chemotherapy, 17, 288-290. https://doi.org/10.1007/s10156-010-0117-x

[30] McInnes, G.T., Lawson, D.H. and Jick, H. (1981) Acute Adverse Reactions Attributed to Allopurinol in Hospitalised Patients. Annals of the Rheumatic Diseases, 40, 245-249. https://doi.org/10.1136/ard.40.3.245

[31] Rosenbloom, D. and Gilbert, R. (1981) Reversible Flu-Like Syndrome, Leukopenia, and Thrombocytopenia Induced by Allopurinol. Annals of Pharmacotherapy, 15, 286-287. https://doi.org/10.1177/106002808101500409

[32] McCrae, K.R. (2003) Thrombocytopenia in Pregnancy: Differential Diagnosis, Pathogenesis, and Management. Blood Reviews, 17, 7-14. https://doi.org/10.1016/S0268-960X(02)00056-5

[33] Kam, P.C., Thompson, S.A. and Liew, A.C. (2004) Thrombocytopenia in the Parturient. Anaesthesia, 59, 255-264. https://doi.org/10.1111/j.1365-2044.2004.03576.x

[34] Parnas, M., Sheiner, E., Shoham-Vardi, I., Burstein, E., Yermiahu, T., et al. (2006) Moderate to Severe Thrombocytopenia during Pregnancy. European Journal of $O b$ stetrics \& Gynecology and Reproductive Biology, 128, 163-168. https://doi.org/10.1016/j.ejogrb.2005.12.031

[35] Klipple, G.L. and Cecere, F.A. (1989) Rheumatoid Arthritis and Pregnancy. Rheumatic Diseases Clinics of North America, 15, 213-239.

[36] Østensen, M. and Villiger, P.M. (2007) The Remission of Rheumatoid Arthritis during Pregnancy. Seminars in Immunopathology, 29, 185-191. https://doi.org/10.1007/s00281-007-0072-5

[37] De Man, Y.A., Dolhain, R.J., Van De Geijn, F.E., Willemsen, S.P. and Hazes, J.M. (2008) Disease Activity of Rheumatoid Arthritis during Pregnancy: Results from a Nationwide Prospective Study. Arthritis Care \& Research, 59, 1241-1248. https://doi.org/10.1002/art.24003 